\title{
ERO-TEMAS' ENTRE PINTURAS Y PAPELES. PRÁCTICAS SEXUALES Y GÉNEROS EN LA PUNA DE JUJUY ENTRE LOS SIGLOS XIV Y XVIII
}

\author{
ERO-TEMAS BETWEEN PAINTINGS AND PAPERS. SEXUAL PRACTICES \\ AND GENDER IN THE PUNA OF JUJUY BETWEEN THE XIV AND XVIII \\ CENTURIES
}

María Carolina Rivet ${ }^{A}$

Este trabajo se enfoca en las escenas de índole sexual presentes en manifestaciones de arte rupestre asociadas a estructuras chullparias en el área de Coranzulí, Puna de la Provincia de Jujuy, Argentina, correspondientes al Período Intermedio Tardío, agregando información etnográfica y documentación histórica. La propuesta reflexiona sobre la comprensión del género en los Andes jujeños en épocas prehispánicas tardías, intentando alejarse de concepciones binarias heteronormadas. Se busca ampliar la comprensión de dichas escenas no solo estrictamente en términos de procreación biológica y fertilidad humana, sino más bien para considerar esos conceptos desde el campo semántico de la reproducción, la suerte, el multiplico tanto del ganado como de los cultivos y las personas.

Palabras clave: género, prácticas sexuales, Puna de Jujuy, períodos prehispánico y colonial.

This work focuses on the sex scenes found in rock art manifestations associated with chullparian structures corresponding to the Late Intermediate Period in the Coranzuli area (Puna of the province of Jujuy, Argentina). By combining archaeological, ethnographic, and historical information, it aims at reflecting on the understanding of gender in the Andes of Jujuy in late pre-Hispanic times, trying to overcome binary heteronormalized conceptions. This can help broaden the understanding of these scenes beyond strictly biological notions of procreation and human fertility by considering these concepts as acting in a semantic field of reproduction, luck, the multiplying of both livestock and crops, as well as people.

Keywords: gender, sexual practices, Puna of Jujuy, PreHispanic and Colonial periods.

\section{INTRODUCCIÓN}

Desde al menos los últimos treinta años, diferentes investigadores (por lo general provenientes de la filosofía y la sociología $)^{2}$ se han replanteado y discutido acerca del paradigma binario sexual imperante en Occidente. Aportes como los de Butler (2007), De Lauretis (2000), Preciado (2002), entre otros, ${ }^{3}$ han sido de fundamental trascendencia para reflexionar y comprender el modo en que concebimos el sexo y el género. Estas nuevas miradas proponen que no existe una correspondencia "natural" o "biológica" entre sexo y género. Ambos son constructos culturales erigidos sobre la base de determinados atributos que cada sociedad selecciona. La visión que supone solo dos sexos, masculino y femenino, se inscribe dentro de nuestra sociedad patriarcal y heteronormada, en la cual se afirma, además, que la persona "tendrá la identidad subjetiva de género de su sexo anatómico y cromosómico, lo expresará y aceptará los roles correspondientes" (Maffía 2003: 6). Incluso, pensar en una categoría de género fija, que una persona desenvuelve a lo largo de su vida, sería también fútil. Butler (2007) plantea que tanto el sexo como el género pueden modificarse, cambiar y redefinirse. Dichas premisas, que regulan nuestras categorías de género

\footnotetext{
A María Carolina Rivet, Conicet, Instituto Interdisciplinario Tilcara, Universidad de Buenos Aires, Tilcara, Provincia de Jujuy, Argentina. ORCID: 0000-0002-5038-7384. E-mail: carolinarivet@hotmail.com
} 
y prácticas sexuales, se han extrapolado en las interpretaciones de las sociedades pretéritas considerando, a mi entender, implícita y erróneamente un carácter universal. De igual manera, es común que concibamos la procreación como fin último y primordial de las relaciones sexuales.

Sexo, género y sexualidad, aunque independientes entre sí y con implicancias diferentes, se vinculan a nivel conceptual y experiencial. De esta manera, la sexualidad no indica sexo ni género, así como el género no indica sexo ni sexualidad. La sexualidad es una práctica social que debe comprenderse dentro de un contexto cultural históricamente situado, que incluye todo tipo de relaciones y actividades, identidades, erotismos y políticas sexuales, considerando no solo el coito y el orgasmo, sino el abanico de posibilidades interpersonales y autoestimuladoras (Voss \& Schmidt 2000).

En este trabajo nos interesa reflexionar sobre la significación y las connotaciones de las prácticas sexuales y la construcción social de los sexos y los géneros en los Andes circumpuneños. Para ello nos enfocaremos en el análisis de imágenes sexuales en el arte rupestre de Coranzulí (Puna de Jujuy, Argentina), y utilizaremos además documentación histórica relativa a nuestra área de estudio. A su vez, tomaremos diferentes ejemplos etnográficos de otras áreas andinas, a los cuales sumaremos crónicas y diccionarios coloniales que nos ayudarán a repensar esta problemática.

La perspectiva de género en la arqueología circumpuneña se ha abordado en los últimos años a partir de diversos trabajos enfocados en el estudio de representaciones presentes en la cerámica (Scattolin 2003, 2005), en el arte rupestre (Gilardenghi 2010; Isasmendi 2018), en placas metálicas (Gluzman 2010) y en el registro bioarqueológico (Baffi \& Seldes 2012; Otero et al. 2020). ${ }^{4}$ En términos generales, estos trabajos han buscado identificar y diferenciar los géneros dentro de un sistema binario heteronormado, a partir de la identificación de parámetros biológicos, tales como penes, vulvas, mamas, estados de gravidez y características antropométricas.

Por lo general, el interés estaba puesto en discutir los roles de género, sus asociaciones con diferentes actividades y espacios, las relaciones de desigualdad y dominación y las jerarquías de los sexos en el pasado. Todas estas investigaciones constituyen importantes avances y aportes invaluables a la problemática, visibilizando a la mujer y sus roles, y exponiendo y discutiendo el sesgo androcéntrico que primaba en los trabajos arqueológicos (Conkey \& Gero 1991; Alberti \& Williams 2005). Considerar que existe una categoría universal de mujer sería caer en un esencialismo, dificultando, en palabras de De Lauretis (2000), la posibilidad de ver las diferencias entre las mujeres, es decir, más allá de una esencia arquetípica femenina. Mención aparte merecen los trabajos de Alberti $(1999,2001,2005)$ quien revisa, sistematiza y aplica las nuevas teorizaciones sobre género y sexo.

Desde nuestro punto de vista, se siguen reproduciendo y extrapolando los esquemas normativos occidentales vigentes en nuestra sociedad. Las interpretaciones ancladas en supuestos de diferenciación sexual basadas en la genitalidad y el correlato de esta con el género, pueden desvirtuar las lecturas y llevar a conclusiones erróneas acerca de identidades y roles de género. Asimismo, son pocos aún los trabajos orientados a estudiar la sexualidad en el pasado. Voss y Schmidt (2000), de acuerdo con Rubin (1984), desarrollaron una serie de razones que, a su entender, obstaculizan dichos estudios, tales como el esencialismo sexual, la priorización de una heterosexualidad reproductiva y tabúes culturales (Joyce 2007).

En este trabajo nos proponemos, entonces, el desafío de ampliar la perspectiva de un enfoque que discute el universalismo del modelo binario, sexual y de género, mujer-varón, basado en las características biológicas dimórficas, propias de nuestras concepciones occidentales, para considerar otras maneras de construir y vivir el sexo y el género en este sector de los Andes.

\section{EL ÁREA DE ESTUDIO}

El área de trabajo se emplaza hacia el sur de la actual localidad de Coranzulí, Puna de Jujuy, Argentina (fig. 1). A partir de prospecciones pedestres hemos relevado en ella una serie de sitios arqueológicos vinculados con un uso residencial correspondiente al Período Intermedio Tardío, los cuales presentan diferentes características con relación a sus conformaciones espaciales. Registramos dos pequeños poblados semiconglomerados (Yerbaijo y Canalita), compuestos por una treintena de recintos circulares, y otros asentamientos, de pequeña escala, que podrían estar asociados con una única unidad doméstica (por ejemplo, Licante). A su vez, identificamos espacios de uso agrícola, paneles de arte rupestre y un número importante de estructuras chullparias distribuidas en 


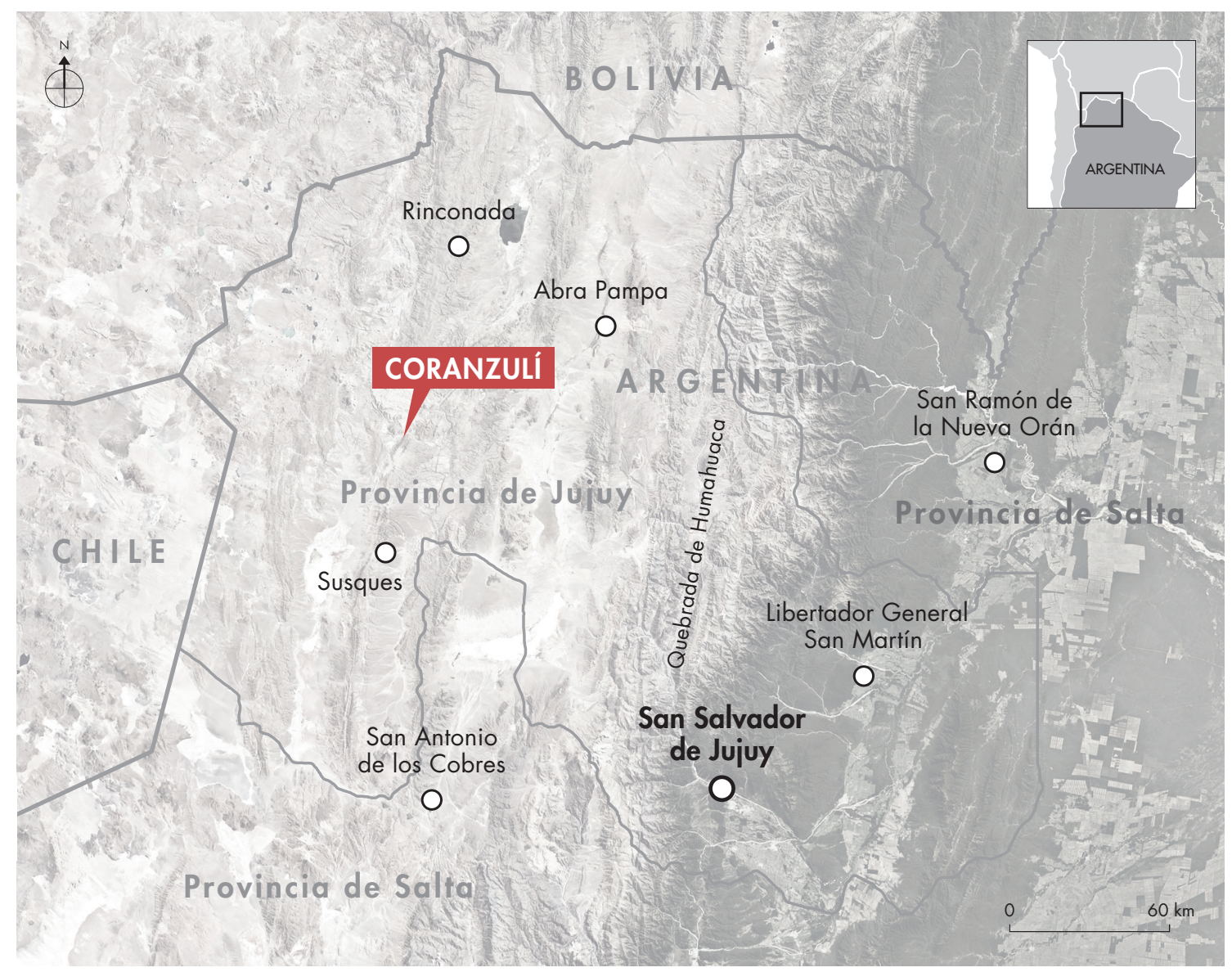

Figura 1. Ubicación del área de estudio. Figure 1. Location of study area.

toda el área. Estos sitios se encuentran en un radio de cinco kilómetros lineales, aproximadamente, y a una altura promedio de $3800 \mathrm{msnm}$, vinculados por medio de diferentes senderos que atraviesan una topografía escarpada. Los fechados radiocarbónicos realizados sobre gramíneas contenidas en el mortero de seis chullpas ubicadas en Licante, posicionan su construcción en torno al siglo XIV DC (Rivet 2015b). En algunos casos, los paneles de arte rupestre se encuentran asociados a espacios con chullpas en el interior de aleros rocosos.

$\mathrm{Si}$ bien al momento no realizamos excavaciones arqueológicas, el material cerámico recuperado en superficie y las características constructivas y morfológicas de las estructuras de los sitios habitacionales vinculan esta área con la cuenca de Miraflores-Guayatayoc, particularmente con el sitio Tucute (Rivet 2018; Albeck 2019).

La ocupación colonial en el área se evidencia por la presencia de pinturas rupestres y arquitecturas chullpa- rias construidas en ese período. A su vez, contamos con unos pocos documentos escritos relativos a Coranzulí. Estos nos han permitido esbozar el derrotero histórico de estos grupos sociales y, en lo que atañe a este trabajo, visualizar otras subjetividades de género, a lo cual nos remitiremos en los acápites finales.

\section{SOBRE ALEROS, CHULLPAS Y ARTE}

Es importante detenernos primero en los espacios que contienen tanto el arte rupestre como las estructuras chullparias. Las cuevas o los abrigos rocosos son lugares que, como veremos, han tenido y tienen significaciones especiales, siendo utilizados muchas veces para llevar a cabo rituales. En acápites posteriores mostraremos cómo ciertas prácticas sexuales eran parte de dichas ceremonias. Por ello, no debemos descartar la posibilidad de 


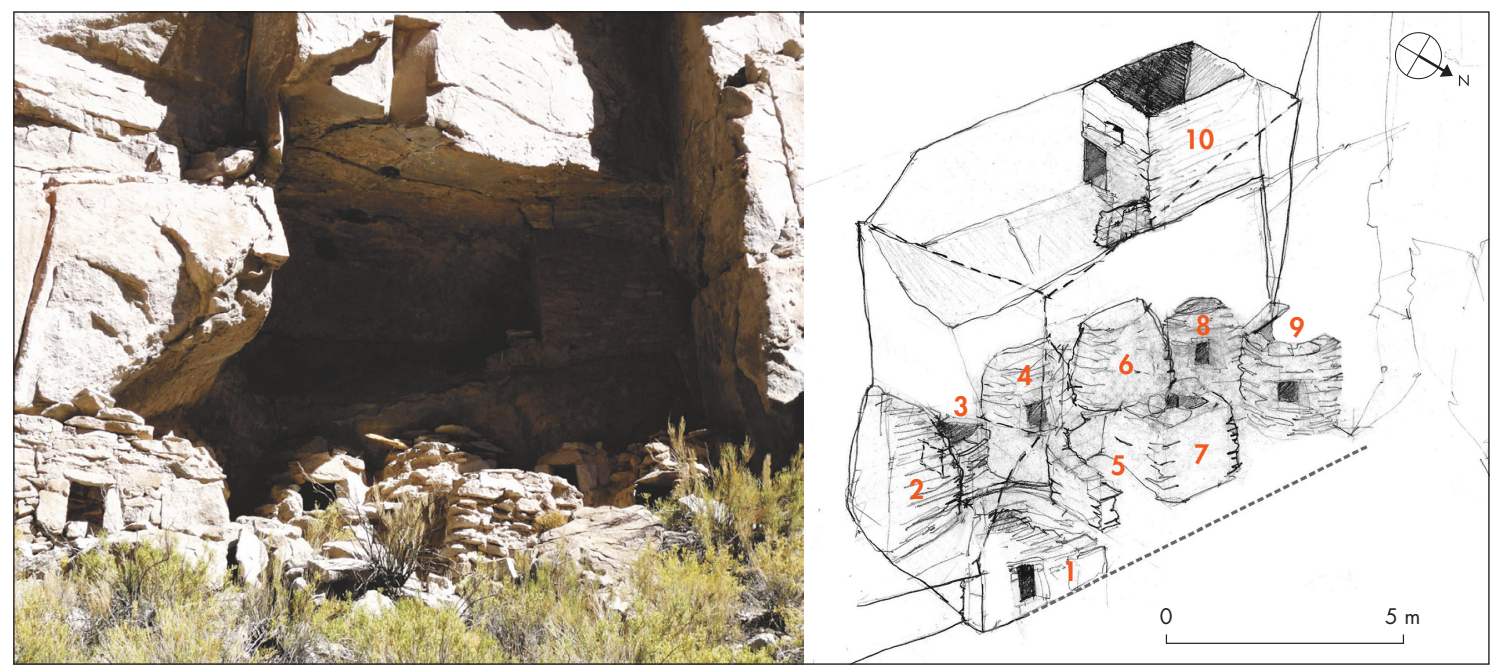

Figura 2. Alero 1. Los números indican las estructuras chullparias. Figure 2. Eave 1. The numbers indicate the chullparian structures.
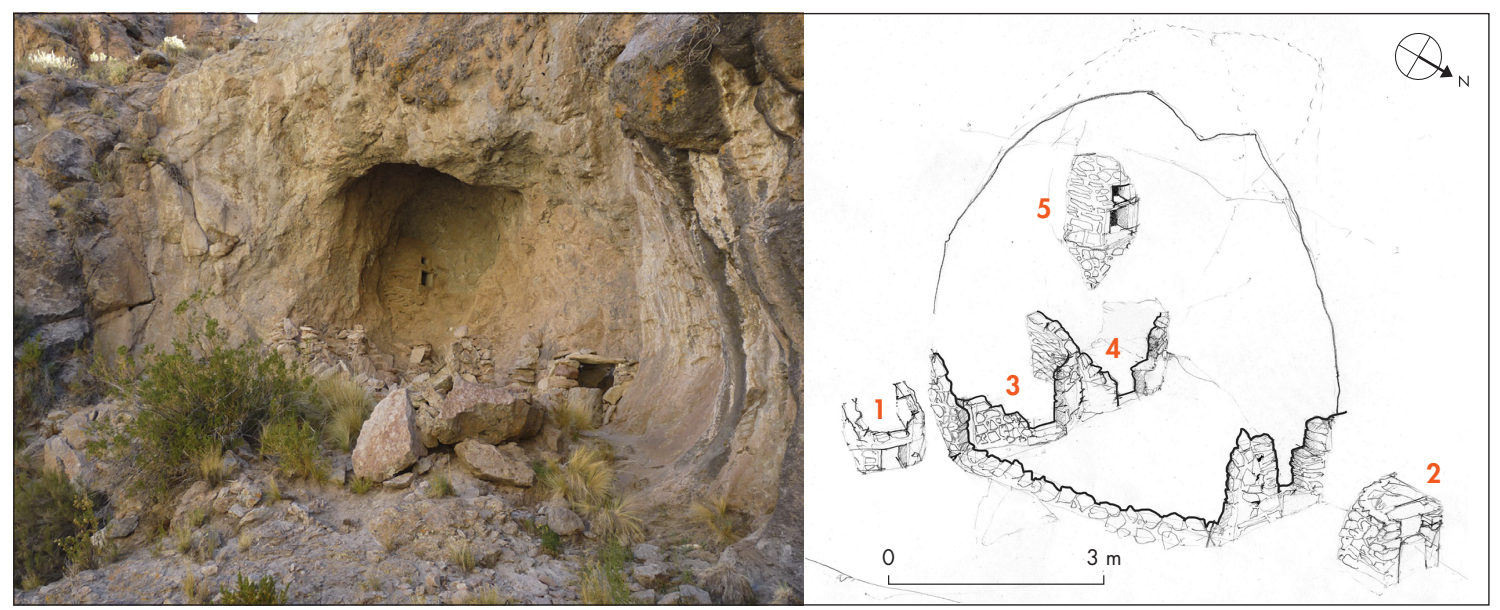

Figura 3. Alero 2. Los números indican las estructuras chullparias. Figure 3. Eave 2. The numbers indicate the chullparian structures.

que en los aleros bajo estudio se haya realizado algún tipo de estas prácticas.

En este trabajo consideraremos para el análisis los aleros 1 y 2 , emplazados en Licante. Existen una serie de aspectos compartidos respecto de las características de estos dos aleros, sus estructuras chullparias y el arte rupestre, que nos hacen pensar en relaciones de transtextualidad. En primer lugar, se encuentran a $1,5 \mathrm{~km}$ uno del otro, ubicados en relación directa con el cauce del río, aprovechando los farellones de ignimbrita que lo delimitan y asociados con senderos que continúan siendo utilizados en la actualidad por las familias para acceder con los rebaños a las diferentes áreas de pasturas.
En términos de organización espacial, si bien presentan una cantidad diferente de estructuras chulparias, en ambos estas se emplazaron aprovechando las paredes rocosas. En los dos aleros hemos podido registrar la existencia de un muro perimetral que envuelve la totalidad del espacio interior y marca un acceso único a través de una abertura. Esto es significativo puesto que, en cierta manera, estos muros prescriben un determinado recorrido y percepción del arte rupestre asociado (figs. 2 y 3 ).

Los conjuntos de arte rupestre se presentan en ambos casos en el interior de los aleros, bajo tres condiciones diferentes: a) en el interior de las estructuras chullparias, 
b) formando parte de los muros de estas, y c) en las paredes rocosas, por fuera de las construcciones. Es decir, la visibilidad de estas manifestaciones plásticas es muy reducida, especialmente en aquellas que se emplazan dentro de las chullpas. Cabe aquí preguntarnos sobre los posibles destinatarios de estas expresiones, teniendo en cuenta la asociación de estas arquitecturas con los ancestros (Nielsen 2008; Rivet 2015a, 2015b).

En relación con los sentidos de las cuevas y los abrigos rocosos, diversos investigadores, entre ellos Martínez (1983), Bouysse-Cassagne y Harris (1987) y Cruz (2012), han propuesto que ciertas topografías como los cerros, las cuevas, los manantiales, poseen capacidades fecundantes, poderes genésicos. Estos lugares han estado altamente ritualizados mediante diferentes prácticas que, con cambios, se han sostenido en el tiempo, incluso hasta la Colonia. Habitualmente estos rituales han incluido la producción de distintas y cambiantes materialidades, tales como el arte rupestre y los objetos arquitectónicos. Incluso, en las crónicas y los documentos coloniales son mencionados como espacios donde se realizaban diferentes cultos y ritos.

Debemos considerar, entonces, al menos la posibilidad de que estos espacios se hayan constituido como lugares de prácticas ceremoniales, con complejas implicancias multisensoriales, si tenemos en cuenta que, como mínimo, lo visual y la práctica tanto de la ejecución de las pinturas como de la construcción de las chullpas podían formar parte de dichas acciones rituales. Asimismo, el emplazamiento de dichas pinturas, dentro y fuera de las estructuras, presenta aberturas con tapas que podían potencialmente ser sustraídas en determinadas instancias. En nuestro caso, todas estas pinturas entraban en el campo de dichas ceremonias (Rivet 2015a), las que probablemente hayan perdurado hasta, por lo menos, entrado el siglo XVIII.

\section{Arte rupestre en los aleros}

El repertorio iconográfico presente en los aleros 1 y 2 es coherente con lo descripto para el Período Intermedio Tardío en el área circumpuneña (Aschero 2000, 2006), registrando pictografías de tamaños pequeños con un tratamiento plano de la pintura, y prevaleciendo entre los motivos más representados el de la figura humana y el camélido. ${ }^{5}$ Tal como mencionamos, dichas manifestaciones plásticas fueron realizadas en las paredes rocosas del interior de los aleros, la mayoría ubicadas dentro de las chullpas, reduciendo su campo visual. Esta copresencia de arte y arquitectura chullparia genera un diálogo que confluye en un relato con puntos en común, en el cual determinadas agencias de los ancestros (corporizados en las chullpas, sensu Nielsen 2008), tales como propiciación de la fecundidad, se ven reforzadas o amplificadas en la narrativa plástica. Es decir, aleros, arte y chullpas se significan mutuamente; se entretejen distintos conceptos en la articulación entre estas estructuras arquitectónicas y las expresiones plásticas.

Los temas que se presentan en el alero $1^{6}$ son diferentes agrupaciones de camélidos, algunos portando pecheras, ${ }^{7}$ y un motivo de coito asociado a un camélido con una saliente debajo de la cabeza, que representaría una pechera. La escena sexual se ubica de forma oblicua por encima del camélido (fig. 4). Todos los conjuntos rupestres prehispánicos se emplazan en el interior de dos chullpas, mientras que los motivos cristianos se ubican por fuera de ellas.

El alero 2 concentra la mayoría de las escenas sexuales, contabilizando 14 en total, además de una gran variedad de representaciones. En uno de los paneles destaca un alineamiento de seis suris, una figura humana con tocado, portando arco y flecha, que está apuntando hacia un camélido superpuesto a otro posible suri, componiendo probablemente una escena de caza. Por encima se ubican al menos dos representaciones de coitos, un escutiforme y dos figuras antropomorfas (fig. 5). Todo el conjunto, a excepción del camélido blanco, fue ejecutado con pintura negra en la pared del alero por fuera de las estructuras chullparias. ${ }^{8}$

En el interior de la chullpa 1 se registran diferentes representaciones, la mayoría pintadas en negro (fig. 6). En la porción inferior del conjunto se distingue un alineamiento de cuatro parejas de figuras antropomorfas "nucleadas", seguidas por otras cuatro figuras individuales, tres de estas con tocados. Encima de estos motivos se ubican otras escenas sexuales, de ellas destaca una en la cual las dos figuras están separadas, una acostada, con las piernas hacia arriba, y la otra de pie al lado, posiblemente representando un momento previo o posterior al coito. Encima de estas escenas se reconoce un motivo de felino a partir de su cola, una cabeza proporcionalmente grande y dos patas representadas por medio de sendos círculos rellenos con múltiples trazos que irradian a modo de garras, vinculadas a otra escena sexual (fig. 7).

A la derecha de este felino, se ubican cuatro figuras humanas con tocados, arcos y flechas, que parecieran 


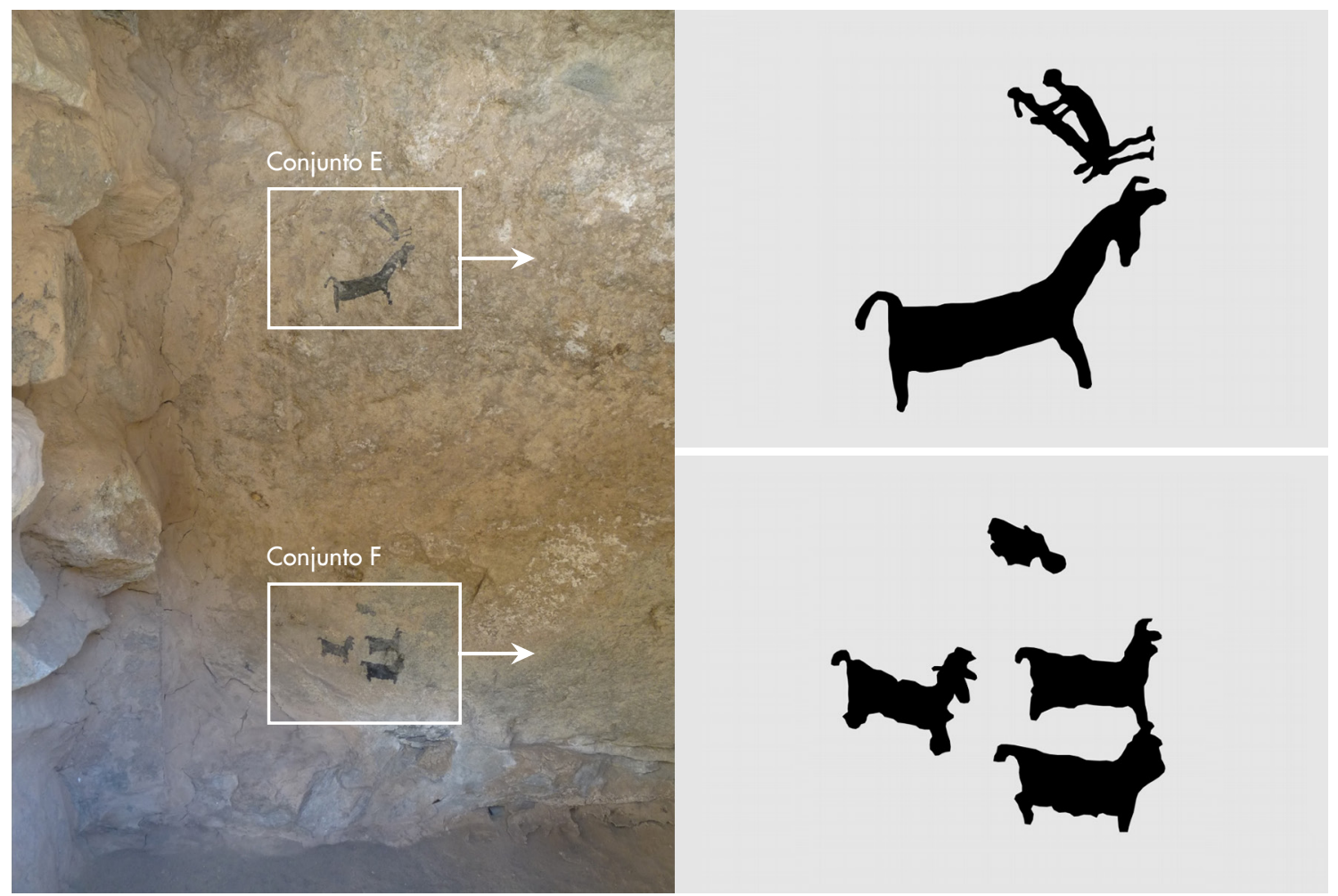

Figura 4. Representaciones al interior de una chullpa en el alero 1. Figure 4. Images inside a chullpa in eave 1.
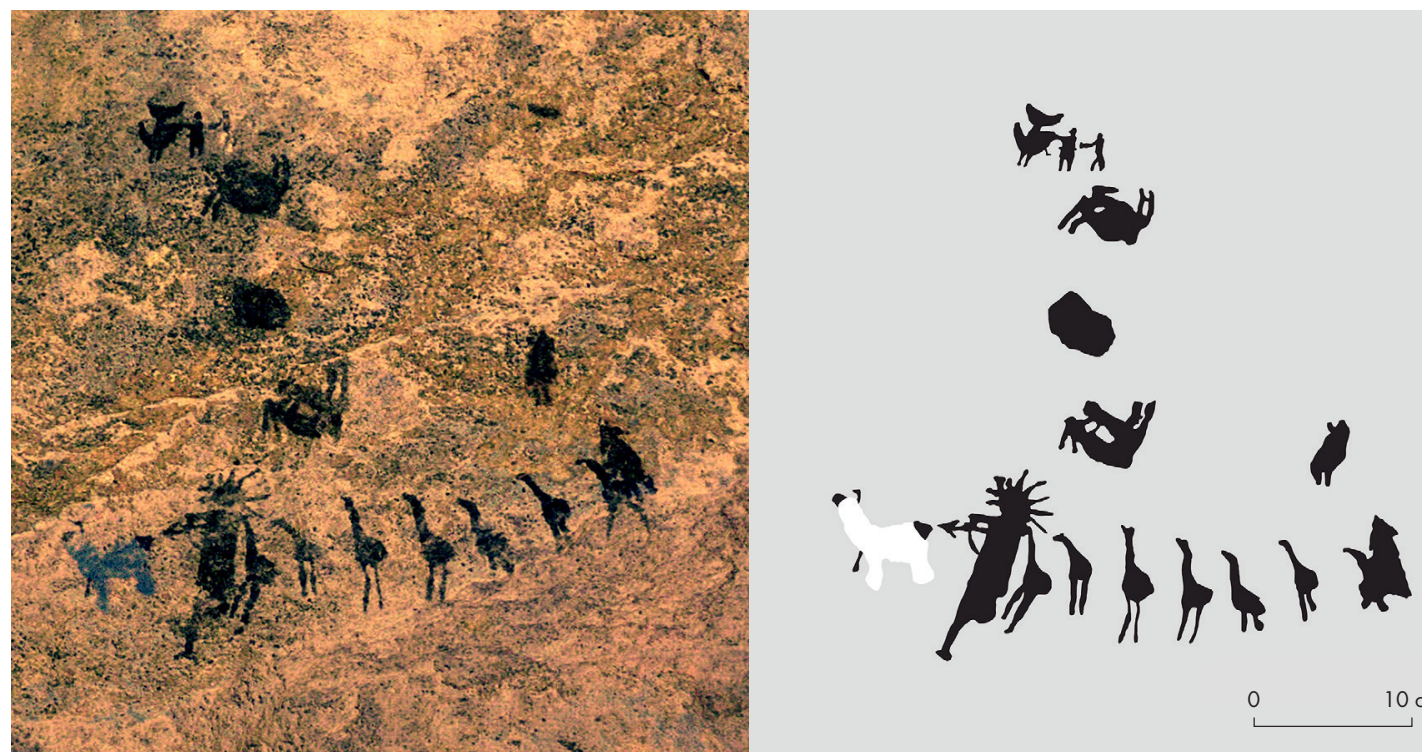

Figura 5. Panel suris. Figure 5. Suris panel. 


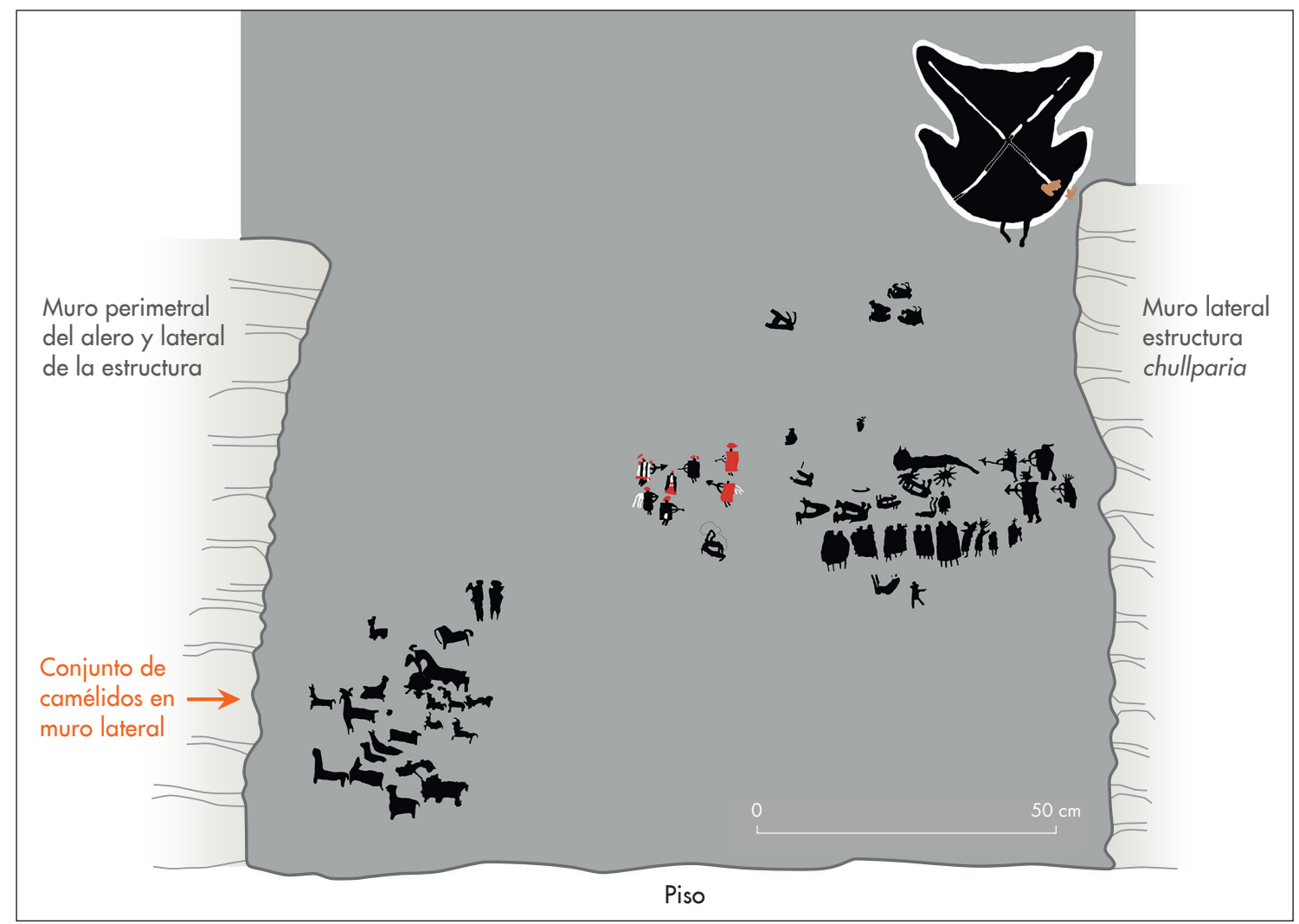

Figura 6. Paneles de arte al interior de la chullpa 1 (alero 2). Figure 6. Art panels inside chullpa 1 (eave 2).
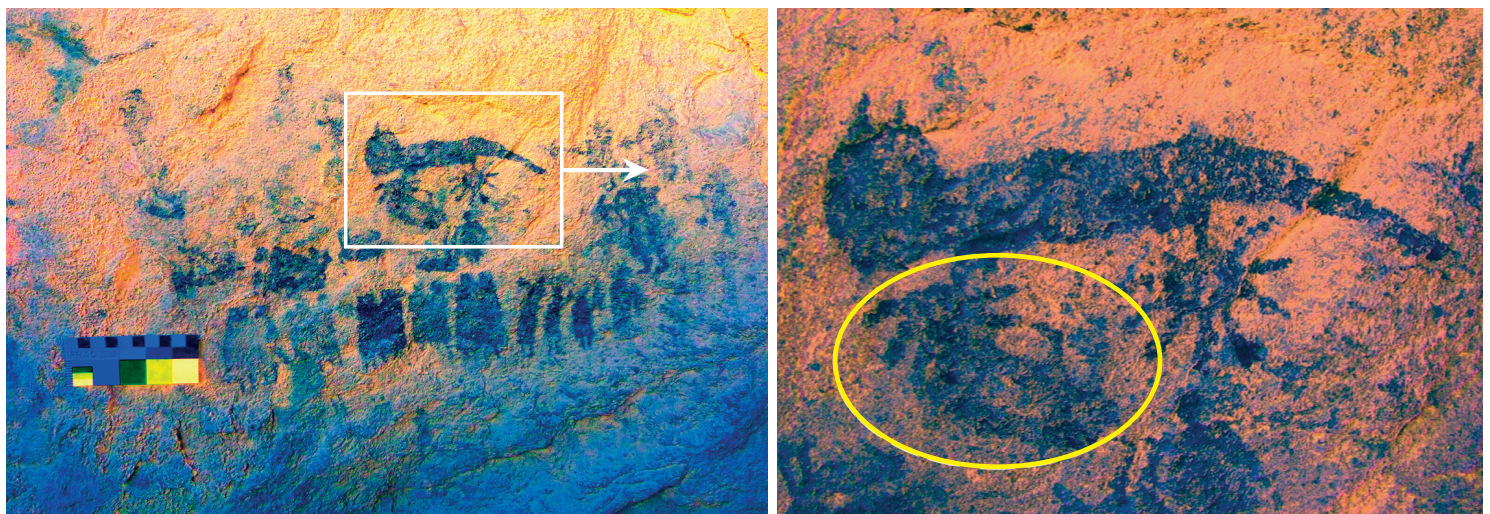

Figura 7. Detalle del motivo del felino y la escena de sexo asociada. Figure 7. Detail of feline motif and the associated sex scene.

apuntar hacia dicho animal. En el interior de la misma estructura chullparia, y a pocos centímetros de los conjuntos descriptos anteriormente, se registra un agrupamiento de camélidos, ${ }^{9}$ algunos de ellos portando pechera, y dos figuras humanas, que podrían corresponderse con la representación de una escena de pastoreo.
A su vez, otro conjunto de camélidos se registra en la cara interna de una de las piedras que conforman el interior del muro de la estructura.

Se completa el repertorio plástico de esta chullpa con una escena de enfrentamiento, policromática, con una configuración circular compuesta por siete figuras 
humanas, seis de las cuales portan arcos y flechas y rodean a la séptima que se encuentra desarmada en el centro de la composición. Todas las figuras presentan rasgos (vestimentas, adornos cefálicos y dorsales) diferentes. Por último, en el extremo superior derecho de la estructura, se ubica un motivo escutiforme de mayor tamaño que el resto de las representaciones descriptas.

\section{Las escenas sexuales en el contexto rupestre}

En términos generales, las representaciones de escenas de coito humano no son tan comunes en el arte rupestre para este sector de los Andes circumpuneños, donde se registraron escenas de cópulas de camélidos y antropomorfos con el sexo marcado o representaciones de vulvas o falos, tal como referimos anteriormente. Escenas de cópula humana muy parecidas a las halladas en Coranzulí fueron registradas en Inca Cueva (Jujuy) ${ }^{10}$ asociadas también a camélidos y suris (Aschero 2000). Debemos entender estas representaciones sexuales en Coranzulí en relación con otros motivos presentes en los aleros, tales como suris y camélidos. En este sentido, asociaciones de genitales (vulvas y glandes) con camélidos y aves han sido referidas para otros sectores del área circumpuneña y comprendidas como parte de la ritualidad pastoril orientada a propiciar la fertilidad y el multiplico de los rebaños (Berenguer \& Martínez 1986; Horta 1996; Berenguer 1999; Aschero 2000).

En Cuipán (La Rioja, Argentina) se ha registrado una figurina modelada en cerámica, de pequeñas dimensiones, representando escenas de sexo entre dos varones, que González (1998) adscribe a Aguada. En este caso están marcados los genitales y uno de los sujetos posee una larga trenza. A su vez, en la cueva de La Salamanca (Catamarca, Argentina) fue registrada una escena sexual entre una persona y un camélido arrodillado, que González (1998) interpreta como una escena de "bestialismo". Si bien estas representaciones corresponden al Período de Integración Regional para el área valliserrana del Noroeste Argentino, nos interesan en tanto muestran la existencia de una diversidad de prácticas que exceden el modelo heterosexual procreante.

En nuestro caso, entre los dos aleros hemos registrado 15 escenas sexuales realizadas con pintura negra plana. Se trata de representaciones de tamaño pequeño, que no superan los ocho centímetros, compuestas por dos figuras humanas, una debajo y otra encima generalmente unidas por brazos y piernas. Los cuerpos están pintados de perfil y, en general, solo la figura que se ubica por debajo presenta las piernas extendidas hacia arriba. La posición de los cuerpos y las extremidades genera un efecto de cierto dinamismo en la escena (fig. 8). Es importante observar que no están indicados los genitales ni rasgos secundarios como los pechos femeninos o las caderas ensanchadas, tal como fueron observadas en algunos antropomorfos en otras áreas como, por ejemplo, Antofagasta de la Sierra (Isasmendi 2018) o los valles calchaquíes (Gilardenghi 2010). Tampoco presentan otros marcadores, como podrían ser ciertos adornos o vestimenta. Entre ambas figuras la única distinción (en algunos casos) es el peinado, pudiendo tener una, dos o ninguna coleta o trenza. La similitud de cada integrante de la pareja es solo eventualmente distinguida por la disposición del cabello, lo cual no nos permite inferir, dentro de una lógica dimórfica, género o sexo. De todos modos, no podemos dejar de lado que se trata de un tópico diferencial entre algunas parejas de las escenas.

Es importante prestar atención a qué se está representando y qué no. Lo que podemos observar es que la genitalidad está ausente, es decir, los cuerpos no son divididos rígidamente, y sobre la base de este criterio, de manera binaria masculino/femenino. Entonces, es la relación sexual lo que está figurado, a la que vamos a entender como una relación social (sensu Absi 2016), imbuida de sentidos y formando parte de redes de relaciones. Es una práctica que pone en juego de manera total los cuerpos, constituyéndose en un acto performático.

Sería fútil pensar que la posición de los cuerpos tiene un correlato en el tipo de relación sexual, entre personas del mismo o distinto sexo, o en las formas del acto sexual (frotamientos, penetración anal o vaginal, por ejemplo), por estar enmarcados en nuestros propios esquemas y costumbres sexuales de raigambre occidental. Ciertas formas de práctica sexual no dan como resultado ciertos géneros (Butler 2007), y viceversa. Vale la pena, entonces, al menos poner en duda una supuesta relación heterosexual en estas imágenes y distanciarnos de la mera identificación genital para ir un poco más lejos y hacernos una serie de preguntas gatilladoras, una serie de erotemas: ¿qué conceptos están operando en estas imágenes rupestres?, ¿qué implicancias y significaciones tenía el acto sexual?, ¿cómo se construían los géneros, cómo se actuaban?, ¿es válido pensar solo en dos géneros limitando la posibilidad de otros? 


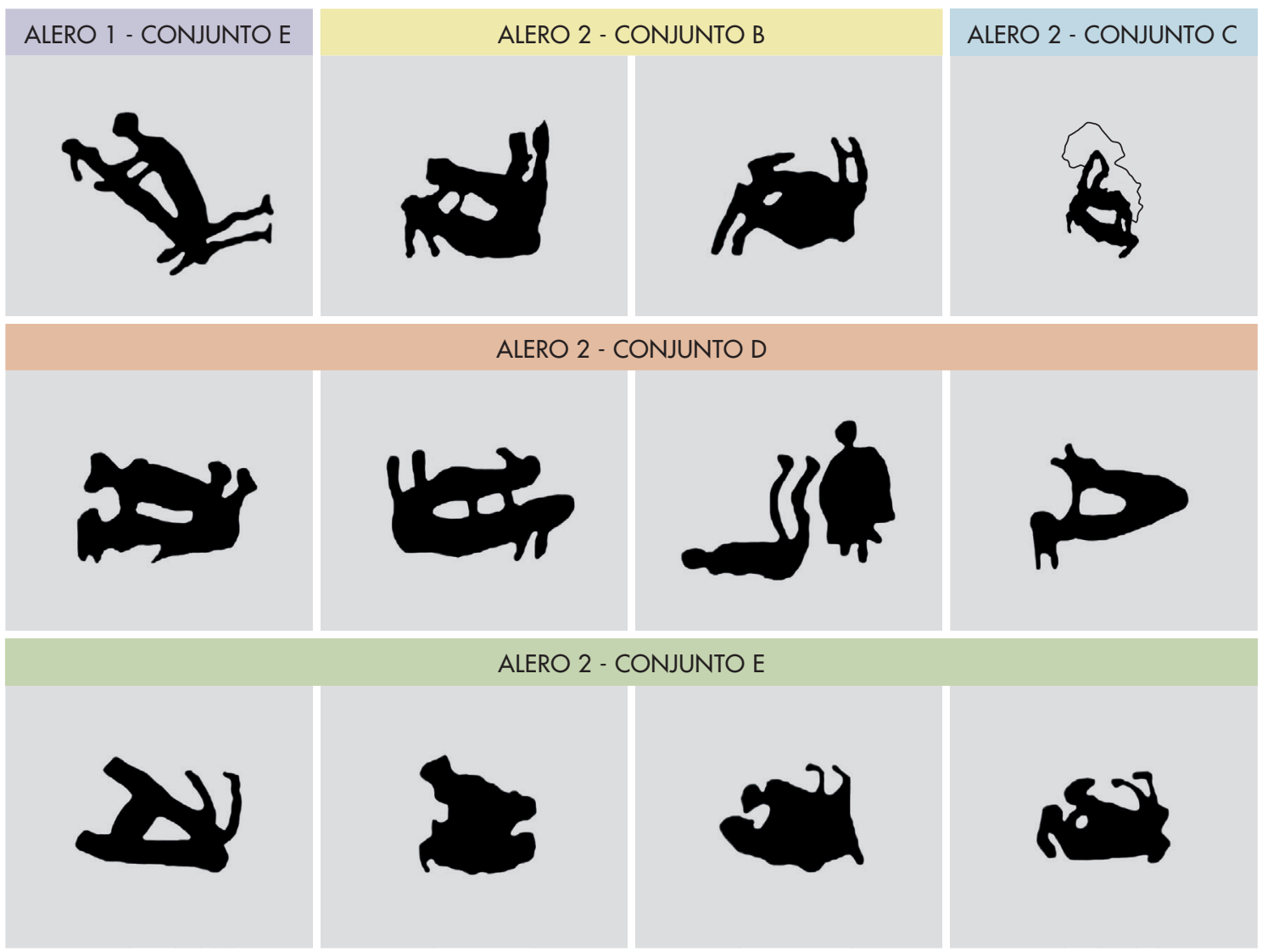

Figura 8. Ejemplos de escenas sexuales en los aleros 1 y 2. Figure 8. Examples of sex scenes in eaves 1 and 2.

Teniendo en cuenta estas escenas rupestres y sus diferentes asociaciones con camélidos, suris y felinos, nos interesa ahora reflexionar sobre la importancia de las prácticas sexuales en las comunidades andinas. Primero, nos acercaremos desde las investigaciones etnográficas, para luego enfocarnos desde los aportes etnohistóricos.

\section{GÉNEROS Y SEXOS EN LOS ANDES}

\section{Géneros, prácticas sexuales y festividades andinas}

Nos concentraremos en las referencias etnográficas que existen para diferentes sectores de los Andes, con la intención de abordar una propuesta interpretativa de las escenas sexuales pintadas en los aleros en particular, y la comprensión andina de la sexualidad, el género y el sexo en lo general.
En los Andes existieron -y existen- muchas maneras de dar vida (no solo la práctica heterosexual) y muchos agentes (no solo las personas humanas). Es decir, no es únicamente el acto sexual con un fin reproductivo en términos biológicos capaz de generar vida. Dentro de una ontología andina, el campo semántico de la fertilidad se presenta amplio y abarcativo, incluyendo prácticas (sexuales o no) que contienen capacidades genésicas y que actúan en el campo amplio de fecundidad y multiplico en términos agrícolas, pastoriles y sociales. Si entendemos la cosmología andina como relacional, es decir, una red en la que todas las entidades se vinculan entre sí (Haber 2010; De Munter 2016), entonces estaremos de acuerdo en que las sexualidades (y sus potencias) de esas diferentes entidades también entran en relación.

En este sentido, las prácticas sexuales humanas se asocian, se proyectan y alcanzan la fertilidad de la tierra y la reproducción del ganado (Van den Berg 1989; Geffroy 2012; Sigl 2012; Isbell 2014), tal como 
lo observaron también los cronistas coloniales en los cultos agrarios y pastoriles, y en rituales de iniciación sexual, que más adelante desarrollaremos. En muchos casos, las personas presentan comportamientos con connotaciones eróticas, mayores licencias sexuales o mayor desinhibición.

Los rituales de marcación de ganado en la Puna de Jujuy son entendidos también como instancias propiciadoras de la fecundidad y el multiplico. Adornos que son colocados en los animales, como flores, chimpus, pecheras y collares están asociados con capacidades genésicas y de protección (Bugallo 2014). En estas instancias de celebración están presentes las danzas y los cantos, las chayas, los sahúmos, el apareamiento simbólico de dos animales (el casamiento) y la wilancha al pintar las caras internas de los corrales con la sangre de un animal sacrificado para tal ocasión. Esta práctica se realiza para la suerte y protección de la hacienda familiar (Mariscotti de Görlitz 1978). ${ }^{11}$ Esta autora refiere a su vez que en estas ceremonias los jóvenes se cubren con cueros y participan de diferentes juegos eróticos.

Si volvemos a las escenas sexuales registradas en los aleros podemos observar cómo varias de ellas se vinculan con camélidos, muchos portando pecheras en sus cuellos, que, tal como vimos, son atributos propiciatorios de fecundidad, protección y suerte, colocados en instancias rituales. Esto, pensamos, plantea una relación entre la sexualidad humana y la propiciación de fertilidad y multiplico del ganado, en línea con lo propuesto por Isbell (2014), en tanto que el sexo entre humanos transferiría su poder fecundador a otras entidades como los animales. Ahora bien, insistimos en que ese acto sexual no necesariamente debe ser procreante para engendrar vida humana. De hecho, como estamos observando, existen muchas prácticas por las cuales se propicia y se genera vida en los Andes, que exceden a la mera reproducción biológica.

La presencia de suris, asociados también a escenas sexuales, no deja de ser interesante al ser animales considerados propiciatorios de agua, lluvia y, por ende, fertilidad (Bugallo 1999; Colatarci 2011). Al día de hoy, aún están presentes, por ejemplo, en las Fiestas Patronales de la Puna de Jujuy, por medio de los samilantes, hombressuri, promesantes de la Virgen o del Santo Patrón. Sus atributos y bailes han sido asociados con el viento y el cambio de clima, y con antiguos rituales propiciatorios de la lluvia, vinculados con la fecundidad y la reproducción (Colatarci 2011). A su vez, sus huevos fueron, y son, utilizados en el ritual de la flechada, es decir, en el ritual de inauguración de una casa y la conformación de una nueva pareja y su reproducción (Bugallo 1999).

Es importante detenernos también en la imagen del felino. Tal como indicó Aschero (2006), las significaciones del felino son altamente polisémicas, siendo asociado con los antepasados y con sus fuerzas fecundantes. A su vez, felinos como los pumas, luego de su muerte, son considerados actualmente en la Puna de Jujuy como pastores protectores de los rebaños de llamas, propiciando su fertilidad (Rivet 2020). Este doble carácter de predador y protector fue señalado también por Saunders (1998). Recordemos, además, la presencia de representaciones de camélidos dentro de la misma chullpa.

En el área aymara, Van den Berg (1989) registró diversos rituales agrícolas y ganaderos en los que, de formas casi explícitas, se relacionaba la fecundidad de la tierra (sembradíos y ganado) con la humana. Por ejemplo, el caso de la danza qhachwa, que se practica en rituales llevados a cabo entre noviembre y marzo, es decir, durante la época de crecimiento de los cultivos. Se trata de un baile nocturno de cortejo y coqueteo entre jóvenes, que Van den Berg (1989: 63-64) interpreta como un rito de fecundidad que influye en la fertilidad de la tierra. Incluso es una danza relatada en el siglo XVII por algunos cronistas como Cobo, que la describe como un baile (cachua) donde mujeres y varones gozan con libertad de sus "deleites carnales" (Cobo 1892 [1653]: 171-172).

El erotismo también está presente en los valles bolivianos quechuas durante noviembre, por medio de la costumbre de la wallun'ka, un columpio gigante ligado a la celebración de los difuntos (Geffroy 2012). Durante esta festividad, colmada de experiencias sensoriales, la sensualidad y los coqueteos se hacen presentes. En palabras de Geffroy, se trata de "un juego de seducción con los muertos" (2012: 87), pero que también promueve la sexualidad entre jóvenes y personas del mismo sexo, que a su vez estimula la fecundación de la Madre Tierra (Geffroy 2012). En Guallatire (norte de Chile), en la década de 1990, durante la celebración de Todos los Santos fue registrada la participación de “dos jóvenes disfrazados de mujer” (Gavilán Vega \& Carrasco 2009: 105).

Diversas investigaciones etnográficas han puesto en evidencia algunos casos que exceden el esquema heteronormado binario, mostrando incluso distintos géneros. La sexualidad en los Andes atraviesa tanto a 
personas humanas como no humanas, de forma tal que entidades como cerros, animales, ríos y ancestros se constituyen como agentes con géneros con capacidad de practicar relaciones sexuales y reproducirse. En este sentido, Cruz (2012) ha planteado que algunas de estas entidades se consideran q'iwa, en tanto poseen en su interior una fuerza germinante (femenino-masculino). En esta misma línea, Sigl (2012:74) entiende que "q’iwa es un ser transfronterizo que se mueve en el espacio liminal entre lo femenino y lo masculino"; es decir, una categoría que no encaja en el modelo binario. De esta forma, un varón con voz aguda o una mujer que se comporta como hombre son q'iwa.

Quizás debamos considerar la posibilidad de la actuación de otros géneros, e incluso de cierta ambigüedad sexual; teniendo en cuenta, además, que el sistema sexogénero con fines solo reproductivos es una imposición por parte de los españoles católicos (Escanilla Cruzat 2019). Para comprender la construcción de género en los Andes, tal como estamos viendo, debemos distanciarnos entonces de un patrón dimórfico. Un buen ejemplo es el trabajo de Rösing (2014) en Amarete (Bolivia), donde menciona la construcción social de 10 géneros, no solo considerando una genitalidad (primer género atribuido al nacer), sino que son otorgados a partir de las características de la chacra o parcela en la que la persona nace. Además, existen géneros "provisionales" que son adjudicados al asumir cargos políticos. Es decir, al género otorgado por el "sexo biológico" se le suman una serie de géneros sociales.

Ahora bien, volviendo a nuestro caso de estudio y como señalamos anteriormente, las escenas sexuales fueron representadas en las paredes rocosas de los aleros $y$, en la mayoría de los casos, en el interior de estructuras chullparias, que encierran los motivos rupestres. El relato que se entreteje entre ambos discursos (el pictórico y el arquitectónico) decanta en el campo semántico de la ancestralidad. En los Andes, todas, o la mayoría de las entidades, tienen género, inclusive los ancestros, los cuales presentan una sexualidad ambigua y un gran poder genésico. De acuerdo con Martínez (1983), los antepasados son andróginos, al igual que wakas, apus y espíritus. Gose (2004) coincide con esta apreciación, pues en sus investigaciones en el sur del Perú observó que "los apus surgen como caracteres esencialmente andróginos, hasta hermafrodíticos" (2004: 309). Incluso en el siglo xviI, Juan de Santacruz Pachacuti hace mención a un "animal muy pintado de todos los colores. Dizen que era apo de los otorongos, en cuya guarda da a los ermofraditas yndios de dos naturas" (1993 [1613]: 158-159).

Esto nos lleva a cuestionar nuestra perspectiva occidental binaria y heteronormada desde la cual miramos, describimos e interpretamos estas imágenes, para comenzar a pensar en términos no polarizados de género. En este sentido, Isbell (2014: 259) sostiene que la androginia "en el esquema andino de género no es simplemente un tipo de complementariedad final. Al contrario, la androginia debería pensarse como una 'sinécdoque': la totalidad andrógina es más grande que la suma de sus partes femeninas y masculinas". ¿Cómo nos representamos una persona andrógina en estos términos?, ¿somos capaces de ver lo que no entendemos?, ¿entendemos la sexualidad en el mundo andino?

Lo que estarían mostrando estos ejemplos es la complejidad que reviste la sexualidad en los Andes, poniendo en evidencia nuestra dificultad para categorizar las diferentes subjetividades de género. El vocablo q'iwa, difícil de definir al interior de nuestra propia concepción occidental de la sexualidad, pone en crisis nuestra propia mirada occidental binaria con la que nos identificamos. Las subjetividades no estaban definidas por criterios sexo-género de la manera en que hoy los concebimos. Ahí radica la dificultad de aprehender las dimensiones que adquiere la sexualidad andina.

Podemos permitirnos al menos la pregunta acerca de si tales representaciones pintadas en los aleros remiten efectivamente a prácticas sexuales entre humanos o si se trata de actos sexuales entre ancestros, es decir, entre personas no humanas quizás con otros géneros, un tercer género, si lo pensamos en el sentido en que Isbell (2014) plantea la androginia. Aquí debemos recordar, por un lado, que en las escenas rupestres analizadas no está representado ni indicado ningún atributo genital, como vulva, pene o pechos. Y, por otro, que la mayor parte de estas pinturas fueron realizadas al interior de chullpas, cuya reducción del campo visual nos hace pensar en que eran los propios ancestros los destinatarios de dichas pictografías.

La relación entre sexo, género y reproducción no siempre es lineal ni debe ser comprendida en términos netamente biológicos. El sexo no reproductivo en los Andes posee también capacidades genésicas, actuando en el campo amplio de la fertilidad y la fecundidad agrícola y pastoril. A continuación nos centraremos en la información proveniente de fuentes coloniales, 
incluyendo un documento relativo a Coranzulí que nos permitirá reflexionar sobre las categorías de géneros y géneros fluidos.

\section{[...] Y en la madriguera de coransuli... ${ }^{12}$}

Coranzulí se conformó en época colonial como un espacio de frontera jurisdiccional entre la Gobernación del Tucumán y el Corregimiento de Atacama, perteneciendo, de acuerdo a las escasas referencias documentales, hasta mediados del siglo xviri a la primera y luego al segundo. La dominación colonial de esta área se produjo de manera tardía y heterogénea. Este emplazamiento liminal ha ocasionado algunas dificultades para las investigaciones etnohistóricas debido a la limitada disponibilidad de documentación escrita. Tal como propusimos en otro trabajo (Gil Montero et al. 2017), se trataba de un territorio poco dominado por los españoles, quedando muchas veces en los márgenes del sistema de control colonial. Este carácter internodal le habría permitido mantener y reproducir determinadas lógicas, prácticas y formas de vida indígenas. Podemos conceptualizar esta área en los términos de Quiroga (2010: 190) como huaycos, es decir, como espacios de refugio y resistencia, que se constituyeron como escenarios de reproducción social. A partir de la documentación disponible, en Coranzulí, hasta bien entrado el siglo xviıI perduraron prácticas indígenas prehispánicas, como el entierro en cuevas, mostrando márgenes de acción y agencias indígenas por fuera del control español.

Sin embargo, en estos aleros hemos registrado manifestaciones plásticas propias de momentos coloniales, específicamente iconografía cristiana, tales como diversos tipos de cruces y motivos que refieren a espacialidades eclesiásticas, como iglesias. A esto se suma una estructura chulparia construida en este período que presenta características morfológicas que la asemejan a una capilla, cuyos muros exterior frontal e interior fueron intervenidos con grabados realizados en la argamasa. En trabajos anteriores propusimos que dichas intervenciones fueron realizadas por indígenas y no por curas extirpadores (Rivet 2013).

En un documento de 1738, correspondiente a la apertura de un juicio criminal hacia varios pobladores de Coranzulí acusados de diferentes delitos, se pide información acerca de un hombre que viste de mujer y está casado con otro hombre. Dicho indio muda de género de mes en mes por "providencia divina":
Fuesele preguntado como se llama adonde bibe un indio que pretesta ser casado con otro yndio que anda bestido de mujer y que estos que bida tienen porque suponen matrimonio y que ladronicias an ejecutado estos dos $\mathrm{O}$ que muertes en el supuesto de ser casados y como se llama al hombre que esta vestida de mujer y si lo conosio antes de bestirse de mujer de hombre y si bio y entendio que motibos tendría para mudar de traje Asi el hombre como la que haze oficio de mujer Y asi mesmo sia oydo sabe o a entendido este malicioso engaño de la capa del matrimonio y responde que la dicha Petrona Laime le ha dicho que un mes es hombre y otro mes mujer por probidencias divinas y el que haze oficio de marido llamado Berna baca le a oydo decir que no puede abitar ni bibir sin la dicha Petrona y que si ronen [?] un rato se quiere ya morir y que no a oydo que ce haigan confesado ni acudido a cosas de yglesia a ninguna parte pero que no a oydo ni sabe si an robado [...] (Archivo de Tribunales de Jujuy [Argentina], 1738, legajo 1145, f. 8r).

Este documento, que nos sitúa en nuestra área de estudio, se refiere a este paraje como madriguera, donde dichas personas se ocultaban protegidas al abrigo de las "serranías ásperas de coransuli". La Real Academia Española en 1780 definió madriguera, en una de sus acepciones, como "el lugar escondido y retirado donde se refugia y esconde la gente de mal vivir, que andan huyendo temerosos de su castigo". Este concepto, creemos, es muy similar al de huayco, analizado por Quiroga (2010) para el área de los valles calchaquíes, en tanto refiere a los espacios de resistencia y de reproducción de la vida indígena. Quizás por esta situación de menor control pervivieron hasta fechas tan tardías ciertas prácticas como el entierro en cuevas, sosteniendo mayores márgenes de acción para vivir su sexualidad sin ser perseguidos y condenados.

Esta cita, además, nos enfrenta a diferentes planos de lectura. Por un lado, la mención de una pareja indígena, que suponen matrimonio, compuesta por dos personas que los españoles identifican como varones, de los cuales uno viste y haze oficio de mujer. Es decir, el género femenino fue reconocido a partir de un determinado atuendo y forma de actuar, de acuerdo a los cánones españoles imperantes en esos momentos, impregnados de concepciones cristianas.

El marco de cotidianeidad que se desprende de la descripción, sumado a las expresiones de sentimientos amorosos - no puede abitar ni bibir sin la dicha Petronanos lleva a pensar que no se trataría de una instancia ritual específica, sino más bien de una manera de vivir. Por otro lado, es interesante resaltar el intercambio periódico de género que hacía una de estas personas. ${ }^{13}$ Estas mudas 
de género nos llevan a plantearnos la posibilidad de que haya sido una categoría fluida, es decir, no fija o estática a lo largo de la vida, respondiendo a una ontología que, seguramente, no concebía solo dos identidades: varón y mujer, y una sola unión sexual procreante.

\section{El pecado nefando}

La existencia de prácticas sexuales no procreantes como las realizadas por personas del mismo género, la masturbación o el sexo anal (entre otras), eran relativamente frecuentes en los Andes, ${ }^{14}$ tal como lo registraron algunos cronistas coloniales bajo el tropo de "sodomía" o "pecado nefando". La sodomía entre los siglos XVI y XVII "constituyó una categoría teológica con consecuencias judiciales" (Molina 2017: 161). Era una categoría confusa, que presentaba una multiplicidad de sentidos: sexo con personas del mismo sexo, coito anal heterosexual, posiciones sexuales indebidas (Molina 2017: 164), prácticas contra natura, bestialismo (Molina [2017: 172] comenta un caso de una persona que mantuvo "trato carnal con una yegua en un huaico"). Es decir, prácticas que atentaban contra el "orden natural" establecido en la Colonia: relaciones matrimoniales heterosexuales cristianamente instituidas que mantenían sexo solo con fines reproductivos. No todas estas prácticas tenían las mismas condenas ni eran perseguidas con el mismo ahínco. Sin embargo, eliminarlas fue uno de los objetivos de la evangelización, tal como se aprecia en los diversos catecismos, confesionarios y sermones que intentaban erradicarlas e imponer un nuevo marco normativo, ejerciendo un control sobre la sexualidad indígena. Por ejemplo, en el Catecismo de 1583 se anota: "Sobre todos estos pecados es el pecado que llamamos nefando o sodomía, que es pecar hombre con hombre, o con mujer no por el lugar natural, y sobre todo esto es el pecar con bestias, con ovejas o perras, o yeguas, que esta es grandísima abominación" (1773 [1583]: 346). Pérez Bocanegra (1631), en su Ritual formulario..., también refiere a la reprensión contra los sodomitas, contra la bestialidad, las poluciones, las relaciones con personas del mismo sexo, entre otras prácticas. Incluso González Holguín (1608: 185) define como "Huauça" al hombre o mujer somético.

Muchas de estas prácticas sexuales se asociaban a instancias rituales o festivas, tal como lo hacen notar algunos cronistas de la época como, por ejemplo, Cieza de León y el Jesuita Anónimo:
[...] en los oráculos y adoratorios donde se daban las respuestas hacía entender que convenía para el servicio suyo que algunos mozos desde su niñez estuviesen en los templos, para que a tiempos y cuando se hiciesen los sacrificios y fiestas solemnes, los señores y otros principales usasen con ellos el maldito pecado de la sodomía (Cieza de León 2005 [1553]: 182).

Permitia que en semejantes juntas de borracheras y bebidas viniesen las mujeres rameras ó solteras que no fuesen vírgines ni viudas, ó las mancebas ó las mujeres legítimas de cada uno, y que en casas ó escondrijos, que por allí habia muchos, cometiesen sus fornicios y torpezas, porque cesasen los incestos, los adulterios y estupros y nefandos (Jesuita Anónimo 1950 [1596]: 178).

Sin embargo, debemos considerar la posibilidad de que las relaciones entre personas del mismo sexo hayan formado parte de su cotidianeidad, tal como podemos observar en el caso de Coranzulí. Incluso debemos contemplar la existencia de otros géneros en los Andes, tal como vimos en algunos ejemplos etnográficos. Escanilla Cruzat (2019) ha mostrado la diversidad de concepciones acerca de sexos, géneros y prácticas sexuales existentes en los Andes coloniales. De hecho, tanto Bertonio (2008 [1612]) como González Holguín (1608), en sus respectivos diccionarios aymara y quechua, definieron diferentes géneros. En ambos casos los géneros son determinados por una combinación que responde a un esquema binario mujer/varón. Cabe preguntarnos si esta limitación no está mediada por los propios esquemas heteronormados cristianos de dichos cronistas, imposibilitándolos de poder percibir o entender una realidad que excedía a sus propios marcos culturales. De esta manera, González Holguín conceptualiza al 'hombre afeminado' en estos términos: "Huarmi hina pissisonco. o cacchannakruna. Hombre afeminado para poco flaco sin fuerça, o brio" (1608: 178), y a la "muger varonil: Ccari hina huarmi" (1608: 229). Por su parte, Bertonio los define de la siguiente manera: "Huaussa, Keussa, Ipa. Vno que vive, viste, habla, y trabaja como muger, y es paciente en el pecado nefando, al modo que antiguamente solia auer muchos en esta tierra" (2008 [1612]: 154); en tanto "Huarccancca, Chachanco Ccacha [es la] Muger atrebida, libre, que mas parece hombre en su hablar, y proceder que muger encogida y que acomete ella al hombre" (2008 [1612]: 151).

Si analizamos las definiciones de Bertonio (2008 [1612]) podemos observar que para describir al "hombre afeminado" incluye sus prácticas sexuales, aspecto que está ausente en la explicación de la "mujer varonil". En 
este último caso, como también en las definiciones de González Holguín (1608), lo que prima es la caracterización performática (sensu Butler 2007), es decir, conductas, modos de hablar, vestir o capacidades físicas.

¿Por qué pensamos que sucede esto? Durante la Colonia la sodomía femenina se mantuvo bastante invisibilizada y a la vez constituyó un punto de discusiones, que incluían también el debate sobre su propia existencia. Si bien se la consideraba un pecado de lujuria, muchos la entendían como "sodomía imperfecta", de menor gravedad que la cópula entre varones (Molina 2014). La mirada falocéntrica de la sociedad colonial cristiana y occidental empañó las prácticas sexuales de las mujeres, consideradas además pasivas en el orden de lo procreacional. Se concebían dos géneros y el sexo debía limitarse a la procreación, y las prácticas que se apartaban de ese fin eran consideradas antinaturales, abyectas, en contra del orden divino (Molina 2017). Las definiciones que acabamos de revisar aluden, en definitiva, a arquetipos genéricos conformados por lenguajes kinésicos que respondían a los esquemas interpretativos coloniales.

\section{PALABRAS FINALES: ¿QUÉ MIRAMOS CUANDO VEMOS?}

En este trabajo se tuvo la intención de reflexionar sobre cómo condicionamos nuestras interpretaciones del pasado bajo nuestros propios presupuestos. Planteamos una serie de interrogaciones retóricas, erotemas, con la expectativa de desandar narrativas. Pensemos, por ejemplo, que dichas escenas sexuales fueron entendidas por Boman (1991 [1908]) a principios del siglo xx como escenas de lucha, o en la manera en que otorgamos sexo y género en la iconografía presente en distintos soportes a partir de la identificación de genitales, respondiendo claramente a un esquema binario y heteronormado. En este sentido, quisimos ampliar la mirada hacia identidades y roles de género diferentes a dicho esquema, distanciándonos de su construcción a partir solo de indicadores biológicos tomados como "naturales" y "universales", y de los estereotipos de género atribuidos. De hecho, en la actualidad, estos esquemas están siendo fuertemente cuestionados y revisados. ${ }^{15}$ De igual forma, pensar que las relaciones sexuales en los Andes tenían solo un fin procreativo en términos estrictamente biológicos sería limitar las posibilidades semánticas de una práctica social imbuida de múltiples sentidos y que incluía no solamente personas humanas. Por lo tanto, no podemos extender acríticamente nuestro marco de concepción y construcción de género y sexo, cuya base es la genitalidad, a las sociedades del pasado.

A lo largo de estas páginas, se intenta poner en evidencia que la lógica sexual y de género andina no respondía exclusivamente a un modelo binario heterosexual reproductivo en términos católicos occidentales, teniendo maneras mucho más complejas. En este sentido, ciertas prácticas sexuales (sin necesariamente fines reproductivos) tenían implicancias genésicas, especialmente las realizadas en contextos rituales, tal como pudimos observar en ejemplos etnográficos y en los textos coloniales.

Por último, hemos presentado dos aproximaciones para discutir el problema planteado. Por un lado, la presencia en el arte rupestre de escenas sexuales emplazadas dentro de aleros rocosos en relación con chullpas, nos hace pensar en un contexto ritualizado donde podrían haberse llevado a cabo dichas prácticas eróticas. Por otro, el documento colonial relativo a Coranzulí nos plantea la posibilidad de la coexistencia de subjetividades que excedían el modelo heteronormado. ¿Cómo interpretaríamos desde el registro arqueológico a esta persona que siendo "varón" viste de "mujer" y muda de género? Muy probablemente sea catalogada como varón, de acuerdo a sus características físicas. Somos conscientes de las dificultades y limitaciones que plantea la propia disciplina y los materiales con los que trabajamos, pero no por ello debemos dejar de preguntarnos y de comenzar a generar marcos interpretativos y metodológicos para abordar esta problemática.

\section{NOTAS}

${ }^{1}$ Juego de palabras. De acuerdo a la RAE una erotema es una interrogación retórica.

${ }^{2} \mathrm{Al}$ respecto, es interesante la reflexión de Taylor (2018), en cuanto la antropología no ha desarrollado teorizaciones propias para abordar la problemática de la sexualidad, debiéndose quizás a las características del trabajo etnográfico.

${ }^{3}$ Muchas de estas nuevas discusiones y planteos toman como punto de partida la obra de Foucault (1976).

${ }^{4}$ Veremos a lo largo de este artículo cómo desde los estudios etnohistóricos y algunos etnográficos se ha avanzado mucho más en comprender las diversidades sexuales y de género en los Andes. 
${ }^{5}$ Ver Rivet (2016) para una descripción más detallada del arte rupestre.

${ }^{6}$ Es en este alero 1 donde se registran motivos pintados de índole cristiana, tales como cruces de calvarios, y una estructura chullparia fechada en época colonial tardía, cuyos muros fueron utilizados como soporte para el grabado en el barro fresco de representaciones de capillas y cruces de diferentes tipos (Rivet 2013).

${ }^{7}$ Las pecheras son adornos confeccionados con lanas de colores que se disponen colgando de los cuellos de los animales, como un jabot. Como veremos más adelante, en la actualidad estos atributos (junto con otros como flores, chimpus y collares) se colocan principalmente durante el ritual de la señalada.

${ }^{8}$ Otro tema representado en la pared del alero, por fuera de las chullpas, es un conjunto de figuras humanas en norma frontal con distintas vestimentas y tocados. Al no estar asociado con escenas de sexo decidimos no tomarlo para este trabajo.

${ }^{9}$ Superpuesto a este agrupamiento se registró la representación de un equino, claramente correspondiente a intervenciones en momentos coloniales.

${ }^{10}$ Véase también Boman (1991 [1908]: 786-789), quien las interpreta como escenas de lucha o como "muertos acostados en el suelo". Éric Boman fue un arqueólogo sueco que se instaló en Argentina y participó a comienzos del siglo xx de dos misiones científicas en la Puna de Atacama (19011902 y 1903). Su obra Antiquités de la région Andine de la République Argentine et du désert d'Atacama fue publicada en 1908 en París; allí da a conocer los resultados de sus expediciones, reuniendo información etnográfica y arqueológica de la región (Benedetti 2005).

${ }^{11}$ Hemos registrado también en nuestra área de estudio diversas señaladas con componentes muy similares a los descriptos para otros sectores de la Puna. A su vez, este tipo de costumbres se registran en toda el área andina.

${ }^{12}$ Archivo de Tribunales de Jujuy, legajo 1145, f. 9.

${ }^{13}$ De todos modos, habría que analizar con mayor profundidad la interpretación que realizan los agentes españoles de esta situación.

${ }^{14} \mathrm{Y}$ también lo eran entre los mismos españoles, incluso al interior del clero (Molina 2017).

${ }^{15} \mathrm{Y}$ están siendo acogidos por los movimientos feministas y de disidencias sexuales que los llevan al campo de los debates y las políticas públicas.

\section{REFERENCIAS}

Absi, P. 2016. Hablando de sexo. Bulletin de l'Institut Français d'Études Andines 45 (3): 363-372.

AlbECK, M. E. 2019. Investigaciones arqueológicas e históricas en Casabindo. Revista del Museo de La Plata 4 (1): 144-182.
Alberti, B. 1999. Los cuerpos en prehistoria. Más allá de la división entre sexo/género. Revista do Museu de Arqueologia e Etnologia, suplemento 3: 57-67.

Alberti, B. 2001. De género a cuerpo: una reconceptualización y sus implicaciones para la interpretación arqueológica. Intersecciones en Antropología 2: 61-72.

Alberti, B. 2005. Diferencia sexual y objetos activos: cuerpos, sexo/género y la cultura material. En Género y etnicidad en la arqueología sudamericana, V. Williams \& B. Alberti, eds., pp. 73-83. Buenos Aires: INCUAPA-UniCEN.

Alberti, B. \& V. Williams 2005. Género y etnicidad en la arqueología sudamericana. Buenos Aires: INCUAPA-UNICEN.

Archivo de Tribunales de Jujuy 1738. Legajo 1145.

Aschero, C. 2000. Figuras humanas, camélidos y espacios en la interacción circumpuneña. En Arte en las rocas. Arte rupestre, menhires y piedras de colores en la Argentina, M. M. Podestá \& M. de Hoyos, eds., pp. 15-44. Buenos Aires: Sociedad Argentina de Antropología.

Aschero, C. 2006. De cazadores y pastores. El arte rupestre de la modalidad Río Punilla en Antofagasta de la Sierra y la cuestión de la complejidad en la Puna meridional argentina. En Tramas en la piedra. Producción y uso del arte rupestre, D. Fiore \& M. M. Podestá, eds., pp. 103140. Buenos Aires: Sociedad Argentina de Antropología.

BAfFi, E. I. \& V. SEldes 2012. La mujer en el registro bioarqueológico y su visibilidad en los contextos funerarios. Comechingonia 16: 53-70.

Benedetti, A. 2005. Un territorio andino para un país pampeano. Geografía histórica del Territorio de los Andes (1900-1943). Tesis para optar al grado de Doctor en Geografía, Facultad de Filosofía y Letras, Universidad de Buenos Aires.

Berenguer, J. 1999. El evanescente lenguaje del arte rupestre en los Andes atacameños. En Arte rupestre en los Andes de Capricornio, J. Berenguer \& F. Gallardo, eds., pp. 9-56. Santiago: Museo Chileno de Arte Precolombino.

Berenguer, J. \& J. L. Martínez 1986. El río Loa, el arte rupestre de Taira y el mito de Yakana. Boletín del Museo Chileno de Arte Precolombino 1: 79-99.

Bertonio, L. 2008 [1612]. Vocabulario de la lengua aymara. La PaZ: IEB-ASDI.

Boman, E. 1991 [1908]. Antigüedades de la región andina de la República Argentina y del desierto de Atacama, vol. 2. Jujuy: Universidad Nacional de Jujuy.

Bouysse-Cassagne, T. \& O. Harris 1987. Pacha en torno al pensamiento aymara. En Tres reflexiones sobre el pensamiento andino, T. Bouysse-Cassagne, O. Harris, T. Platt \& V. Cereceda, eds., pp. 11-59. La Paz: Hisbol.

Bugallo, L. 1999. La maison fléchée: conception de l'habitat sur le haut-plateau argentin. En Cultures et habitats. Douze contributions á une ethnologie de la maison, E. Pierre, ed., pp. 61-76. París: L'Harmattan.

BugAllo, L. 2014. Flores para el ganado. Una concepción puneña del multiplico (Puna de Jujuy, Argentina). En 
Comprender los rituales ganaderos en los Andes y más allá: Etnografía de lidias, herranzas y arrierías, J. Rivera Andía, ed., pp. 311-363. Bonn: Bonner Amerikanistische Studien.

ButLer, J. 2007. El género en disputa: el feminismo y la subversión de la identidad. Barcelona: Paidós.

Cieza de León, P. 2005 [1553]. Crónica del Perú. El señorío de los Incas. Caracas: Biblioteca Ayacucho.

Сово, В. 1892 [1653]. Historia del nuevo mundo, vol. III. Sevilla: Sociedad de Bibliófilos Andaluces.

Colatarci, M. A. 2011. Tiempo y espacio en las celebraciones $y$ rituales del noroeste argentino. Buenos Aires: AAEA.

Conkey, M. \& J. Gero 1991. Tensions, pluralities and engendering archaeology: an introduction to women and prehistory. En Engendering archaeology. Women and prehistory, J. Gero \& M. Conkey, eds., pp. 3-30. Oxford: Basil Blackwell.

Cruz, P. 2012. El mundo se explica al andar. Consideraciones en torno a la sacralización del paisaje en los Andes del sur de Bolivia (Potosí, Chuquisaca). Indiana 29: 221-251.

De Lauretis, T. 2000. Diferencias. Etapas de un camino a través del feminismo. Madrid: Horas y Horas.

De Munter, K. 2016. Ontología relacional y cosmopraxis, desde los Andes. Visitar y conmemorar entre familias aymara. Chungara 48 (4): 629-644.

Escanilla Cruzat, N. 2019. "Varones en abito de mugeres": Análisis comparativo de las concepciones de sexo/género que co-existieron durante los siglos Xvi y xvi en los Andes. Informe de Seminario para optar al grado de Licenciado en Historia, Facultad de Filosofía y Humanidades, Universidad de Chile.

Foucault, M. 1976. Historia de la sexualidad. Vols., I, II y III. Madrid: Siglo XXI.

Gavilán Vega, V. \& A. M. Carrasco 2009. Festividades andinas y religiosidad en el norte chileno. Chungara 41 (1): 101-112.

Geffroy, C. 2012. El erotismo de la wallunka: la historia de un diálogo con los muertos y de un coqueteo con los vivos. Arqueoantropológicas 2 (2): 79-96.

Gil Montero, R., M. C. Rivet \& R. Longui 2017. Las visitas coloniales y los espacios internodales: propuestas para la interpretación de sus silencios. Estudios Atacameños 56: 273-297.

Gilardenghi, E. 2010. Los nenes con los nenes, las nenas con las nenas: relaciones de género en el arte rupestre del sitio Los Cerrillos, Valle Calchaquí Norte (Pcia. de Salta, Argentina). La Zaranda de Ideas 4: 71-89.

GLUZMAN, G. 2010. Representación humana y género en piezas de metal del Noroeste Argentino. Boletín del Museo Chileno de Arte Precolombino 15 (2): 89-106.

González, A. R. 1998. Cultura de La Aguada. Arqueología y diseños. Buenos Aires: Filmediciones Valero.

GonzÁlez Holguín, D. 1608. Vocabulario de la lengua general de todo el Peru llamada lengua Qquichua, o del Inca. Ciudad de los Reyes [Lima]: por Francisco del Canto.
Gose, P. 2004. Aguas mortíferas y cerros hambrientos. Ritos agrarios y formación de clases en un pueblo andino. Quito: Abya Yala.

Haber, A. 2010. Animismo, relacionalidad, vida: perspectivas post-occidentales. En Biografías de paisajes y seres. Visiones desde la arqueología sudamericana, D. Hermo \& L. Miotti, eds., pp. 75-98. Catamarca: Encuentro Grupo Editor.

Horta, H. 1996. Taira: definición estilística e implicancias iconográficas de su arte rupestre. Chungara 28 (1): 395-417.

Iglesia CatóliCa 1773 [1583]. Tercer Catecismo y exposición de la doctrina cristiana por sermones para que los curas $y$ otros ministros prediquen y enseñen a los indios y a las demás personas: conforme a lo que se proveyó en el Santo Concilio Provincial de Lima el año pasado de 1583. Mandado a reimprimir por el Concilio Provincial del año de 1773. Lima: en la oficina de la calle de San Jacinto.

IsASMENDI, M. C. 2018. Un estudio de género en el arte rupestre de la Quebrada de las Pitas, Antofagasta de la Sierra (Catamarca, Argentina). Tesina de grado para optar al título de Arqueóloga, Universidad Nacional de Tucumán.

IsBELL, B. J. 2014. De inmaduro a duro: lo simbólico femenino y los esquemas andinos de género. En Más allá del silencio: las fronteras de género en los Andes, D. Arnold, ed., pp. 253-300. La Paz: ILCA.

Jesuita anónimo 1950 [1596]. Relación de las costumbres antiguas de los naturales del Pirú. Asunción del Paraguay: Editorial Guarania.

JoyCE, R. A. 2007. Embodied subjectivity: gender, femininity, masculinity, sexuality. En A companion to social archaeo$\log y$, L. Meskell \& R. W. Preucel, eds., pp. 82-95. Malden, MA: Blackwell.

Maffía, D. 2003. Introducción. En Sexualidades migrantes. Género y transgénero, D. Maffía, comp., pp. 5-8. Buenos Aires: Feminaria Editora.

MARIscotTI DE GörLITZ, A. M. 1978. Pachamama Santa Tierra. Contribución al estudio de la religión autóctona en los Andes centro-meridionales. Supl. 8. Ibero-Amerikanisches Institut. Berlín: Indiana.

Martínez, G. 1983. Los dioses de los cerros en los Andes. Journal de la Société des Américanistes 69: 85-115.

MolinA, F. 2014. Femina cum femina. Controversias teológicas, jurídicas y médicas en torno a la sodomía femenina en el mundo hispano (siglos XVI-XVII). ARENAL 21 (1): 153-176.

Molina, F. 2017. Cuando amar era pecado. Sexualidad, poder e identidad entre los sodomitas coloniales (Virreinato del Perú, siglos XVI-XVII). Lima: IEFA.

Nielsen, A. E. 2008. The materiality of ancestors. Chullpas and social memory in the late prehispanic history of the south Andes. En Memory work: archaeologies of material practices, B. Mills \& W. H. Walker, eds., pp. 207-231. Santa Fe: School of American Research Press.

Otero, C., L. Fuchs, N. Centeno, S. Gheggi, V. Seldes \& K. Knudson 2020 Ms. Comportamiento mortuorio durante la caída del Imperio Inca en el Pucará de Tilcara (Quebrada 
de Humahuaca, Jujuy). Aportes desde la Entomología forense y la Bioantropología.

Pérez Bocanegra, J. 1631. Ritval Formvlario, E Institvcion De Cvras, Para Administrar A Los Natvrales De este Reyno, los santos Sacramentos del Baptismo, Confirmacion, Eucaristia, $y$ Viatico, Penintencia, Extremavncion, y Matrimonio, Con aduertencias muy necessarias. Lima: por Geronymo de Contreras, iunto al Conuento de santo Domingo.

Preciado, P. B. 2002. Manifiesto contra-sexual. Madrid: Opera Prima.

QUIROGA, L. 2010. En sus huaycos y quebradas: formas materiales de la resistencia en las tierras de Malfín. Memoria americana 18 (2): 185-209.

Real Academia Española 1780. Diccionario de la lengua castellana compuesto por la Real Academia Española, reducido á un tomo para su mas fácil uso. Madrid: Joaquín Ibarra.

Rivet, M. C. 2013. Cruces e iglesias en un contexto chullpario. Arte rupestre colonial en las tierras altas atacameñas. Nuevo Mundo Mundos Nuevos [en línea], Debates. <https://doi. org/10.4000/nuevomundo.64960> [consultado: 31-07-2021].

Rivet, M. C. 2015a. Espacialidades chullparias. Aproximación a los ancestros desde la materialidad (Coranzulí, Jujuy, Argentina). Estudios Atacameños 50: 105-129.

Rivet, M. C. 2015b. La textura de los ancestros. Reflexiones en torno a las lógicas y sentidos de las estructuras chullparias (Coranzulí, Provincia de Jujuy, Argentina). Boletín del Museo Chileno de Arte Precolombino 20 (1): 73-90.

Rivet, M. C. 2016. Arte en contextos chullparios. Primera aproximación a las manifestaciones rupestres de Coranzulí (Jujuy, Argentina). Boletín SIARB 30: 68-83.

Rivet, M. C. 2018. An approach to spatial configuration in the regional developments period in the Coranzulí area (Jujuy Province, Argentina). En Political landscapes of the Late
Intermediate Period in the south-central Andes, A. Álvarez Larrain \& C. Greco, eds., pp. 219-246. Cham: Springer.

Rivet, M. C. 2020. Un león entre la hacienda. Relaciones entre animales y humanos a partir del estudio de pumas embalsamados en la Puna de Jujuy (Argentina). Diálogo Andino 63: 137-150.

Rösıng, I. 2014. Los diez géneros de Amarete, Bolivia. En Más allá del silencio. Las fronteras de género en los Andes, D. Arnold, ed., pp. 77-92. La Paz: ILCA.

SAnta Cruz Pachacuti Yamqui, J. 1993 [1613]. Relación de antiguedades deste reyno del Piru: Estudio etnohistórico y lingüístico. Lima: IFEA.

SAUNDERs, N. J. 1998. Introduction: Icons of power. En Icons of power: feline symbolism in the Americas, N. Saunders, ed., pp. 1-8. Nueva York: Routledge.

Scattolin, M. C. 2003. Representaciones sexuadas y jerarquías sociales en el noroeste argentino prehispánico. Acta Americana 11 (1): 30-48.

Scattolin, M. C. 2005. La mujer que carga el cántaro. En Género y etnicidad en la arqueología sudamericana, V. Williams \& B. Alberti, eds., pp. 43-72. Buenos Aires: INCUAPA-UNICEN.

SIGL, E. 2012. Erotismo, sexualidad y humor en las danzas del altiplano boliviano. Maguaré 26 (2): 51-86.

TAYlor, A. C. 2018. ¿Cómo simetrizar la etnografía de lo íntimo? AVÁ 32: 19-34.

VAN DEN BERG, P. J. M. 1989. 'La tierra no da así no más': los ritos agrícolas en la religión de los aymara-cristianos de los Andes. Amsterdam: CEDLA.

Voss, B. L. \& R. A. Sснмidt 2000. Archaeologies of sexuality: an introduction. En Archaeologies of sexuality, R. A. Schmidt \& B. L. Voss, eds., pp. 1-32. Londres: Routledge. 